\title{
Ein paar Geburtstagsfragen an das Bundesverfassungsgericht
}

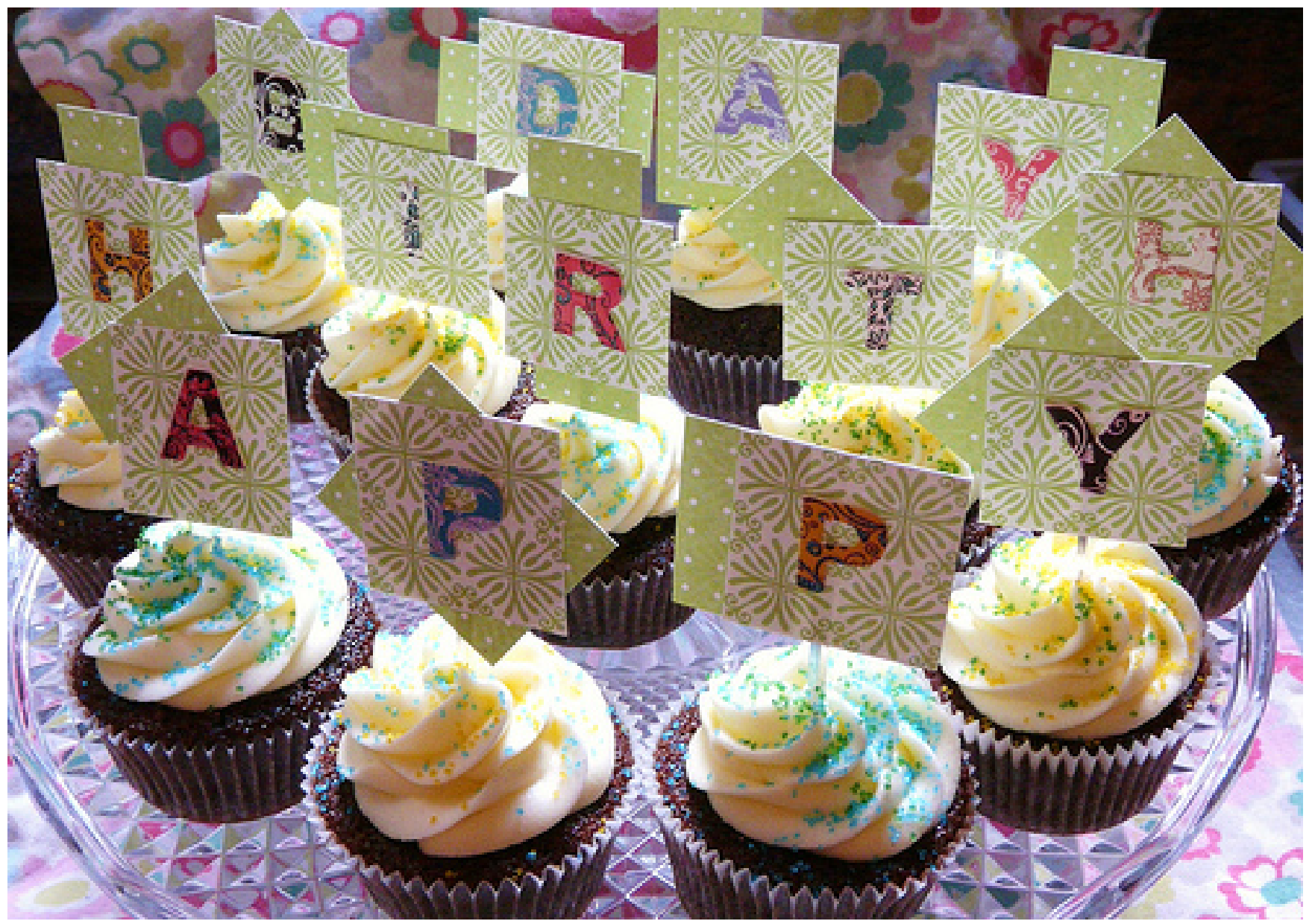

Das BVerfG wird 60 heute. Wir alle finden das Gericht super und sind sehr froh, dass es da ist und uns nicht mit den Innenministern dieser Welt alleine lässt. Deshalb vorweg und von Herzen: Alles Gute!

Wenn ich mir aber den schrillen Jubel betrachte, der in dieser Woche allerorten losbricht anlässlich des Karlsruher Jubiläums, möchte ich doch, ohne die Geburtstagsstimmung allzu sehr zu stören, ein paar schüchterne Fragen stellen wollen:

- Als in der ZDF-Sendung neulich, lieber Herr Voßkuhle, begleitet von den Klängen barocker Hofmusik in extenso der Frage nachgegangen wurde, wie die Prachtgewänder Ihrer Kollegen - "siebeneinhalb Meter Stoff im exklusiven Weinrot, Venezia-Futter, die Knopfleiste verdeckt" - gewartet werden, ist Ihnen da nicht ein bisschen mulmig geworden? Oder wie Sie vorher im ARDBeitrag an der Seite des neben Ihnen herdienernden Frank Bräutigam über die 
Baustelle im Schlossbezirk stiefelten wie einst König Ludwig in Neuschwanstein - haben Sie sich da wirklich von ganzer republikanischer Seele wohl dabei gefühlt?

- Noch eins, Herr Voßkuhle: Im ZDF-Interview sagten Sie, bei Neuwahlen wäre das BVerfG "im Zweifel aufgerufen, einen verfassungsmäßigen Zustand herbeizuführen", was das immer noch verfassungswidrige Bundeswahlgesetz betrifft. Und auf die Nachfrage, ob das heiße, Sie wollten es selber machen, wenn die Politik es nicht tue, haben Sie zustimmend genickt. Das habe ich aber schon richtig verstanden, dass Sie nicht vorhaben, die vom Weimarer Reichspräsidenten auf Sie übergegangene Zuschreibung als "Hüter der Verfassung" so auszulegen, dass Sie sich daraus eine Art NotGesetzgebungskompetenz auf den Leib schneidern. Oder?

- Als Sie, lieber Heribert Prantl, die letzte SZ am Wochenende dann im Druck gesehen haben, mit der roten Robe ohne Mensch drin, aber mit Engelsflügelchen und unter der beziehungsreichen Überschrift "Die letzte Instanz", kam Ihnen das nicht im Nachhinein dann doch ein bisschen albern vor? Und dass Sie das BVerfG als "Gnadenort" bezeichnen, wo das "Wunder" des enormen Vertrauens der Deutschen in dieses Gericht gewirkt wurde meinen Sie nicht, dass Ihnen da ein bisschen was durcheinander geraten ist? Ein Gott, der die von inm geschaffenen Naturgesetze außer Kraft setzt zum Zeichen seiner Souveränität - war es diese Art Wunder, die Sie da im Sinn hatten?

- Lieber Rolf Lamprecht, auch Ihnen herzlichen Glückwunsch für Ihr Buch "Ich gehe bis nach Karlsruhe". Ist schön geworden. Völlig zu Recht und in komplettem Einklang mit dem gängigen Narrativ schildern Sie das BVerfG als einen Ort, wo "die Republik ... wie eine Klasse von ABC-Schützen ... das demokratische Alphabet lernte". Aber wissen Sie, was ich mich frage? Wie ist das eigentlich heute? Was ist eigentlich im Jahr 2011, wo Adenauer schon bald ein halbes Jahrhundert tot ist, so wahnsinnig demokratisch daran, ein Gelehrten-Gremium aus 16 weisen Männern und Frauen, das im Geheimen debattiert und seine Ratschlüsse ex cathedra verkündet, mehr zu verehren als das eigene Parlament?

So, jetzt will ich aber nicht länger stören. Eine schöne Feier wünsche ich heute abend! Ich gehe nicht hin, bin sowieso erkältet. Ich nehme mir lieber ein gutes Buch, das von Oliver Lepsius et. al. zum "entgrenzten Gericht" zum Beispiel, und mache es mir gemütlich. 